\title{
Strategic Reason for Employing Workers with Public Service Motivation
}

\author{
Wakana Hatada, Tomomichi Mizuno \\ Faculty of Economics, University of Nagasaki, Sasebo City, Nagasaki, Japan \\ Email: hatada@sun.ac.jp, rinri@sun.ac.jp
}

Received June $20^{\text {th }}$, 2013; revised July $23^{\text {rd }}$, 2013; accepted August $7^{\text {th }}, 2013$

\begin{abstract}
Copyright (C) 2013 Wakana Hatada, Tomomichi Mizuno. This is an open access article distributed under the Creative Commons Attribution License, which permits unrestricted use, distribution, and reproduction in any medium, provided the original work is properly cited.
\end{abstract}

\begin{abstract}
We construct a simple game-theoretic model in which one private firm and one public (or state-owned) firm compete in quantity of goods produced or service provided. The private and public firms each decide how many workers with public service motivation they will employ as part of an incentive scheme. We assume that both firms produce homogeneous goods with a quadratic cost function but that the private firm is more efficient than the public firm. Both firms are faced with linear inverse demand. We show that whether public firms employ more workers with public service motivation than private firms depends on the efficiency gap between the public and private sectors. This result explains why some literature in public administration reports a significant difference in public service motivation between employees in the private and public sectors and the other literature does not.
\end{abstract}

Keywords: Public Service Motivation; Oligopoly; Strategic Hiring Policy; Efficiency Gap

\section{Introduction}

One of the important issues in the literature of public administration is whether employees of public (or state-owned) firms and those of private firms are different in terms of work-related values, reward preferences, needs, and personality types (Wittmer, 1991). Following a prominent study of public service motivation (Perry \& Porter, 1982; Perry, 1996, 1997), many papers study this issue ${ }^{1}$. However, overall, empirical studies on this issue do not have consistent results. That is, some studies show that employees of public and private firms are different, but other studies do not show this. For example, while Rainey (1982) reports a difference in preferences regarding the value put on helping others, Gabris and Simo (1995) show that there is no difference between workers in the public and private sectors.

In order to explain why we cannot obtain robust evidence about the difference in public service motivation between workers in the public and private sectors, we provide a gametheoretic model. Analyzing this model, we show that the strategic incentive to employ workers with public service motivation and the disparity in efficiency between the public and private sectors accounts for the difference. That is, whether public firms employ more workers with public service motivation than private firms do depends on the efficiency gap between public and private firms.

Our approach is relevant to the issue of delegation in microeconomic theory and game theory (Vickers, 1985; Fershtman \& Judd, 1987). In the delegation model, the objective of the principal is not the same as that of his agent. Thus, the principal creates an incentive scheme for the agent. In our model, the

\footnotetext{
${ }^{1}$ For the survey on public service motivation, see Perry (2000).
}

owners and governors of the firms in the public and private sectors decide how many workers with public service motivation to employ. This decision works as a commitment of the incentive scheme. This point is in contrast to previous studies.

This paper is organized as follows. In the next section, we present the model. The third section calculates the equilibrium. The final section offers a conclusion.

\section{The Model}

We provide a simple game-theoretic model. We assume a public service market (e.g., the education industry or security industry) where one private firm (firm $P$ ) and one state-owned firm (firm S) compete in quantity of goods produced or service provided $^{2}$. In each firm, there is an owner (or governor) as principal and a manager (or public servant) as agent. For the private firm, the owner wants to maximize its profit; for the stateowned firm, the governor wants to maximize social welfare ${ }^{3}$. In order to maximize the owner's objective, the owner (or governor) designs the objective function of the manager (or servant) as the incentive scheme. For simplicity, following Vickers (1985), we assume that the manager's and servant's objective function $\left(u_{P}\right.$ and $\left.u_{S}\right)$ designed by owner and governor are:

$$
\begin{aligned}
& u_{P}=\theta_{P} x_{P}+\left(1-\theta_{P}\right) \pi_{P}, \\
& u_{S}=\theta_{S} x_{S}+\left(1-\theta_{S}\right) \pi_{S},
\end{aligned}
$$

\footnotetext{
${ }^{2}$ The assumption that there is only one private firm in the market is not essential for our results. We can extend the model to an oligopoly market with many firms.

${ }^{3}$ The oligopoly model with profit-maximizing private firms and welfaremaximizing public firms is called a mixed oligopoly model. For surveys on the mixed oligopoly model, see De Fraja and Delbono (1989) and Vickers and Yarrow (1988).
} 
where $x_{i}$ is the output of firm $i, \pi_{i}$ is the profit of firm $i$, and $\theta_{i}$ is the incentive scheme chosen by the owner (or governor) of firm $i(=P, S)^{4}$.

We can interpret $\theta_{i}$ as the degree to which a private or state-owned firm employs workers with public service motivation. The reason is explained as follows. If the firm employs many workers with public service motivation, the firm will tend to provide more public service. In other words, more workers with public service motivation means a larger value of $\theta_{i}(i=P, S)$. Since the owner or governor can decide whom to hire, they indirectly choose the level of $\theta_{i}$ through their hiring policy.

Given the incentive scheme, the manager chooses the output. We consider the quadratic cost of firms: $\gamma x_{P}^{2}$ for a private firm and $x_{S}^{2}$ for a state-owned firm, where $\gamma$ denotes the difference in efficiency. Since in many industries, private firms are more efficient than state-owned firm, we assume $0 \leq \gamma \leq 1$. We assume that the firms produce homogeneous goods and that they face linear inverse demand: $z=1-x_{P}-x_{S}$, where $z$ is price.

Under these setting, the profits of firms are:

$$
\begin{gathered}
\pi_{P}=\left(1-x_{P}-x_{S}\right) x_{P}-\gamma x_{P}^{2}, \\
\pi_{S}=\left(1-x_{P}-x_{S}\right) x_{S}-x_{S}^{2} .
\end{gathered}
$$

Social welfare is $S W=C S+\pi_{P}+\pi_{S}$, where the consumer surplus is $C S=\left(x_{P}+x_{S}\right)^{2} / 2$. Then, the maximization problems of owner, governor, manager, and servant are $\max _{\theta_{P}} \pi_{P}$, $\max _{\theta_{S}} S W, \max _{x_{P}} \theta_{P} x_{P}+\left(1-\theta_{P}\right) \pi_{P}$, and $\max _{x_{S}} \theta_{S} x_{S}+\left(1-\theta_{S}\right) \pi_{S}$, respectively. The timing of the game is as follows. In the first stage, the owner (or governor) of firm $i(=P, S)$ chooses the incentive scheme $\theta_{i}$. After the manager (or servant) of firm $i$ observes the incentive scheme, they choose the output $x_{i}$ in the second stage. We solve the model using backward induction.

\section{Calculating Equilibrium}

In the second stage, the maximization problems of manager and servant are:

$$
\begin{gathered}
\max _{x_{P}} \theta_{P} x_{P}+\left(1-\theta_{P}\right)\left[\left(1-x_{P}-x_{S}\right) x_{P}-\gamma x_{P}^{2}\right], \\
\max _{x_{S}} \theta_{S} x_{S}+\left(1-\theta_{S}\right)\left[\left(1-x_{P}-x_{S}\right) x_{S}-x_{S}^{2}\right] .
\end{gathered}
$$

The first-order conditions lead to the outcome in the second stage:

$$
\begin{aligned}
& x_{P}=\frac{3-4 \theta_{S}+\theta_{P}}{\left(1-\theta_{S}\right)\left(1-\theta_{P}\right)(7+8 \gamma)}, \\
& x_{S}=\frac{1+\theta_{S}+2 \gamma-2 \theta_{P}(1+\gamma)}{\left(1-\theta_{S}\right)\left(1-\theta_{P}\right)(7+8 \gamma)} .
\end{aligned}
$$

In the first stage, the maximization problems of owner and

\footnotetext{
${ }^{4}$ One might think that the incentive scheme of the state-owned firm should be a convex combination of the output and social welfare. In this case, the governor of a state-owned firm chooses the incentive scheme that causes the servant to maximize social welfare. That is, the objective functions of the governor and servant are the same in equilibrium. Even so, the owner of the private firm chooses a positive $\theta_{P}$. Hence, our main result is robust to this modification.
}

governor are:

$$
\begin{gathered}
\max _{\theta_{P}}\left(1-x_{P}-x_{S}\right) x_{P}-\gamma x_{P}^{2}, \\
\max _{\theta_{S}} \frac{\left(x_{P}+x_{S}\right)^{2}}{2}+\left[\left(1-x_{P}-x_{S}\right) x_{P}-\gamma x_{P}^{2}\right] \\
+\left[\left(1-x_{P}-x_{S}\right) x_{S}-x_{S}^{2}\right] .
\end{gathered}
$$

Note that the governor maximizes social welfare $S W$. Putting the outcome in the second stage into these maximization problems and using the first-order condition, we obtain the outcome in the first stage:

$$
\begin{aligned}
& \theta_{P}= \begin{cases}\frac{4(1+\gamma)}{35+86 \gamma+48 \gamma^{2}} & \text { if } \quad \gamma \geq \frac{1}{8}, \\
\frac{3}{27+32 \gamma} & \text { otherwise. }\end{cases} \\
& \theta_{S}= \begin{cases}\frac{-3+22 \gamma+16 \gamma^{2}}{28+104 \gamma+64 \gamma^{2}} & \text { if } \gamma \geq \frac{1}{8}, \\
0 & \text { otherwise. }\end{cases}
\end{aligned}
$$

This result is illustrated in Figure 1. In this figure, the private firm employs more workers with public service motivation if $\gamma$ is small, and fewer workers with public service motivation if $\gamma$ is large. When the private firm is more efficient, $\gamma$ is closer to zero. Hence, the equilibrium structure of employment depends on the difference in the firms' efficiency. Solving $\theta_{P}>\theta_{S}$ for $\gamma$, we have the following proposition.

Proposition: $\theta_{P}>\theta_{S}$ if and only if

$\gamma<(\sqrt{193}-9) / 16 \approx 0.3058$.

The intuition behind this proposition is explained as follows. In our model, large $\theta_{i}(i=P, S)$ works as a commitment device for large output. When the private firm is quite efficient ( $\gamma$ is small), the private firm obtains high gain from this commitment because of large margin (price minus marginal cost). Hence, the private firm with small $\gamma$ tends to set a large value for $\theta_{P}$. This means that the private firm employs many workers with public service motivation. On the other hand, since the state-owned firm maximizes social welfare, it is concerned about efficient production. That is, if the private firm is quite efficient, the state-owned firm wants to move production from the state-owned firm to the private firm. For this to happen, the state-owned firm must commit to a small output. In other words, the state-owned firm chooses small $\theta_{S}$. Hence, in this case, the state-owned firm employs fewer workers with public service motivation. The converse of above argument is

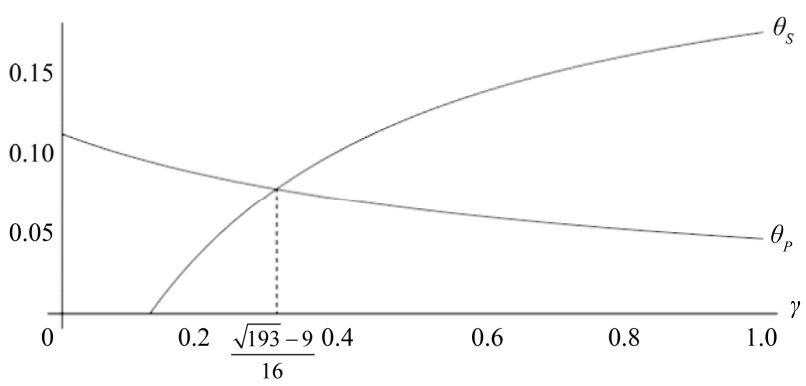

Figure 1.

Equilibrium choice of $\theta_{i}$. 
also true: the private firm chooses small $\theta_{P}$ and the stateowned firm chooses large $\theta_{S}$, when the private firm is inefficient ( $\gamma$ is large). Therefore, in the converse case, the stateowned firm employs more workers with public service motivation than does the private firm.

Our result can provide an explanation for why some literature reports significant difference in public service motivation between employees in the private and state-owned sectors and other literature does not. Since each study uses data from a different industry, the efficiency gap between private and state-owned firms is different in each study. With regard to our results, in order to obtain robust evidence about the relationship between the type of firm (private versus state-owned) and the level of public service motivation in workers, we need to control for the strategic effect of hiring policy. If we used data on the efficiency gap between private and state-owned firms and estimated the relationship between the type of firm and the level of public service motivation of workers, we could remove this strategic effect of hiring policy from the estimated results.

\section{Conclusion}

We consider a simple model and show that the equilibrium tendency of employing workers with public service motivation depends on the difference between public and private firms' efficiency levels. Hence, we provide the answer for why previous literature on public service motivation cannot obtain robust evidence on the difference between workers in the public and private sectors. Since we focus on the strategic reason for employing workers with public service motivation, we use a gametheoretic model. However, every industry is not oligopolistic. Therefore, in order to answer our question in competitive industries, we should create a model without strategic interaction. Although this issue is important, it is a consideration for future research.

\section{Acknowledgements}

We thank financial support from University of Nagasaki. The second author gratefully acknowledges financial support from the Ministry of Education, Science, Sports and Culture in the form of a Grant-in-Aid for Young Scientists (B). Needless to say, all remaining errors are ours.

\section{REFERENCES}

De Fraja, G., \& Delbono, F. (1989). Alternative strategies of a public enterprise in oligopoly. Oxford Economic Papers, 41, 302-311.

Fershtman, C., \& Judd, K. L. (1987). Equilibrium incentives in oligopoly. American Economic Review, 77, 927-940.

Gabris, G. T., \& Simo, G. (1995). Public sector motivation as an independent variable affecting career decisions. Public Personnel Management, 24, 33-51.

Perry, J. L. (1996). Measuring public service motivation: An assessment of construct reliability and validity. Journal of Public Administration Research and Theory, 6, 5-22. http://dx.doi.org/10.1093/oxfordjournals.jpart.a024303

Perry, J. L. (2000). Bringing society in: Toward a theory of publicservice motivation. Journal of Public Administration Research and Theory, 10, 471-488. http://dx.doi.org/10.1093/oxfordjournals.jpart.a024277

Perry, J. L., \& Porter, L. W. (1982). Factors affecting the context for motivation in public organizations. Academy of Management Review, 7, 89-98.

Rainey, H. G. (1982). Reward preferences among public and private managers: In search of the service ethic. American Review of Public Administration, 16, 288-302. http://dx.doi.org/10.1177/027507408201600402

Vickers, J. (1985). Delegation and the theory of the firm. Economic Journal, 95, 138-147. http://dx.doi.org/10.2307/2232877

Vickers, J., \& Yarrow, G. (1988). Privatization: An economic analysis. Cambridge, MA: MIT Press.

Wittmer, D. (1991). Serving the people or serving for pay: Reward preferences among government, hybrid sector, and business managers. Public Productivity \& Management Review, 14, 369-383. http://dx.doi.org/10.2307/3380953 